\title{
Microstructural and Mechanical Characterization of Shear Formed Aluminum Alloys for Airframe and Space Applications
}

\author{
L.P. Troeger ${ }^{1}$, M.S. Domack ${ }^{2}$, and J.A. Wagner ${ }^{2}$ \\ ${ }^{1}$ NRC/NASA Langley Research Center, Mail Stop 188A, Hampton, VA 23681 \\ ${ }^{2}$ NASA Langley Research Center, Mail Stop 188A, Hampton, VA 23681
}

Keywords: Shear forming, roll forming, aluminum alloys, microstructure, texture. Abstract

Advanced manufacturing processes such as near-net-shape forming can reduce production costs and increase the reliability of launch vehicle and airframe structural components through the reduction of material scrap and part count and the minimization of joints. The current research is an investigation of the processing-microstructure-property relationship for shear formed cylinders of the $\mathrm{Al}-\mathrm{Cu}-\mathrm{Li}-\mathrm{Mg}-\mathrm{Ag}$ alloy 2195 for space applications and the $\mathrm{Al}-\mathrm{Cu}-\mathrm{Mg}-\mathrm{Ag}$ alloy $\mathrm{C} 415$ for airframe applications. Cylinders which have undergone various amounts of shear-forming strain have been studied to assess the microstructure and mechanical properties developed during and after shear forming.

\section{Introduction}

Near-net-shape manufacturing technologies represent attractive alternatives to traditional machining methods for airframe and launch vehicle structures [1]. The advantages of near-net-shape manufacturing include a reduction in the amount of material scrap in the form of machining chips and the elimination of thick-plate microstructures, which results in improved mechanical properties. Shear forming, also known as roll forming, is a near-net-shape manufacturing technique in which seamless cylindrical structures are produced by reducing the wall thickness and extending the length of ring-shaped preforms [2-3]. Shear forming was originally developed for steel; the shear forming of aluminum is in the early stages of development. The two methods of shear forming discussed herein are the counter-roller method and the mandrel method which are illustrated in Figure 1 [3]. The materials used in this study were processed and shear formed by Ladish Co. of Cudahy, Wisconsin. The results for the two alloys discussed here are not meant to be directly compared, since each represents a different stage in the development of the aluminum shear forming process.
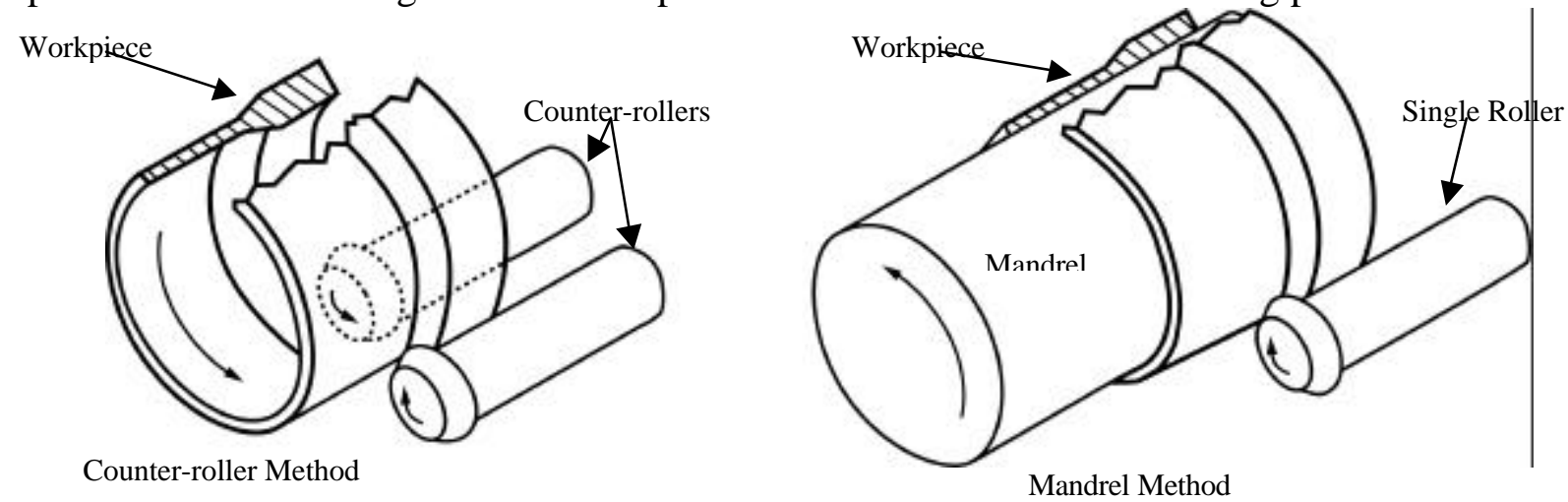

Figure 1. Diagram of shear forming processes [3]. 


\section{Experimental Procedure}

Ladish converted a 2195 ingot to a billet, back-extruded a hollow cylinder, then ring rolled the cylinder to the desired diameter (14 feet) prior to counter-roller shear forming. The material was progressively shear formed into three segments $(\mathrm{D}, \mathrm{A}$, and $\mathrm{C}$ ), each of which was less than 12 inches long. The 2195 cylinder composition is shown in Table 1, along with the 2195 composition used for the Space Shuttle Super Lightweight External Tank (SLWT) [4] which will be used for comparison of mechanical properties [5]. Both alloys fall within the allowable 2195 composition range [6]. A summary of cylinder thicknesses and imposed shear-forming true strains is shown in Table 2. After forming, the cylinders were solution heat treated by Ladish and shipped to NASA Langley Research Center (LaRC). The cylinders were characterized in the as-received (T4) and T8 tempers.

Table 1. 2195 Alloy Compositions. (Weight \%)

\begin{tabular}{|l|l|l|l|l|l|l|}
\hline Alloy 2195 & $\mathrm{Cu}$ & $\mathrm{Li}$ & $\mathrm{Mg}$ & $\mathrm{Ag}$ & $\mathrm{Zr}$ & $\mathrm{Al}$ \\
\hline $\begin{array}{l}\text { Shear Formed } \\
\text { Cylinder }\end{array}$ & 3.90 & 1.00 & 0.34 & 0.30 & 0.14 & Bal. \\
\hline SLWT Plate [4] & 4.00 & 1.00 & 0.40 & 0.40 & 0.12 & Bal. \\
\hline $\begin{array}{l}2195 \text { Composition } \\
\text { Range [6] }\end{array}$ & $3.70-4.30$ & $0.80-1.20$ & $0.25-0.80$ & $0.25-0.60$ & $0.08-0.16$ & Bal. \\
\hline
\end{tabular}

Table 2. Summary of Alloy 2195 Cylinder Thicknesses and Shear-Forming True Strains.

\begin{tabular}{|c|c|c|c|c|}
\hline $\begin{array}{c}\text { Cylinder } \\
\text { Segment }\end{array}$ & $\begin{array}{c}\text { Starting } \\
\text { Thickness } \\
\mathrm{t}_{1} \text { (in.) }\end{array}$ & $\begin{array}{c}\text { Ending } \\
\text { Thickness } \\
\mathrm{t}_{2} \text { (in.) }\end{array}$ & $\begin{array}{c}\text { Strain } \\
\text { Increment } \\
\varepsilon_{\mathrm{i}}=\ln \left(\mathrm{t}_{1} / \mathrm{t}_{2}\right)\end{array}$ & $\begin{array}{c}\text { Total Shear- } \\
\text { Forming Strain } \\
\varepsilon=\Sigma \varepsilon_{\mathrm{i}}\end{array}$ \\
\hline $\mathrm{D}$ & 0.75 & 0.375 & 0.69 & 0.69 \\
\hline $\mathrm{A}$ & 0.375 & 0.25 & 0.41 & 1.10 \\
\hline $\mathrm{C}$ & 0.25 & 0.15 & 0.51 & 1.61 \\
\hline
\end{tabular}

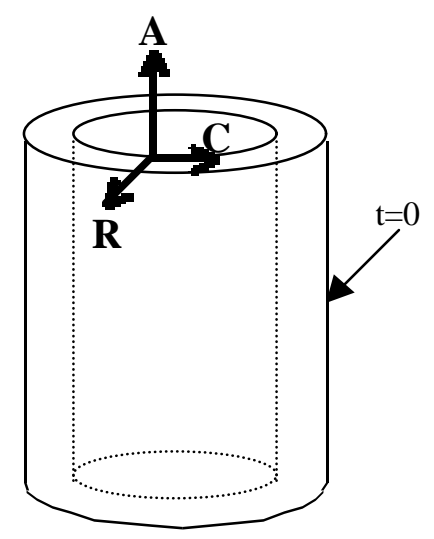

Figure 2. Cylinder coordinate system showing (A)xial, (R)adial, and $(\mathrm{C})$ ircumferential axes.
Ladish processed the $\mathrm{C} 415$ shear formed cylinders using the mandrel shear forming approach. The $\mathrm{C} 415$ composition is $5.00 \mathrm{Cu}-0.80 \mathrm{Mg}-0.50 \mathrm{Ag}-0.13 \mathrm{Zr}-0.60 \mathrm{Mn}-$ $0.06 \mathrm{Fe}-0.04 \mathrm{Si}$ wt.\%; balance is Al. Two C415 ingots were converted to round billets, then back-extruded to produce hollow, cylindrical preforms. The preforms were then machined on the inner diameter to fit the mandrel. The preforms were not ring rolled prior to shear forming. The C415 cylinders were 10.5 inches in diameter and about 4 inches long and were shear formed independently to various thicknesses. Table 3 summarizes the cylinder thicknesses and shear-forming strains. Ladish solution heat treated and stretched the cylinders $3 \%$ prior to shipment to LaRC, where they were subsequently stored at room temperature for over a year. The $\mathrm{C} 415$ cylinders were characterized in the asreceived (T3) temper and two versions of the T8 temper, either directly aged from $\mathrm{T} 3$ to $\mathrm{T} 8$ or resolutionized, stretched, and aged to the T8 temper. The coordinate system for the shear-formed cylinders is shown in Figure 2. 
Table 3. Summary of Alloy C415 Cylinder Thicknesses and Shear-Forming True Strains. $\left(\mathrm{t}_{\mathrm{i}}=0.5\right.$ inches $)$

\begin{tabular}{|c|c|c|}
\hline Cylinder & Wall Thickness, $\mathrm{t}_{\mathrm{f}}$ (inches) & $\varepsilon=\ln \left(\mathrm{t}_{\mathrm{i}} / \mathrm{t}_{\mathrm{f}}\right)$ \\
\hline 1 & 0.244 & 0.72 \\
\hline 4 & 0.127 & 1.37 \\
\hline 3 & 0.095 & 1.66 \\
\hline 6 & 0.076 & 1.88 \\
\hline
\end{tabular}

For both alloys, the grain structure and texture were examined at depths of $t / 8, t / 2$, and $7 \mathrm{t} / 8$ below the outer $(t=0)$ cylinder surface. Full-thickness AR sections were also examined for some conditions. Orientation Distribution Function (ODF) plots were generated from pole figures using Philips PC-Texture software.

Blanks were cut from the 2195 and C415 cylinders to facilitate thermomechanical treatment. The $\mathrm{C} 415$ cylinders required flattening prior to processing due to their small radius of curvature. For both alloys, axial and circumferential subsize tensile specimens were machined from the blanks after processing to the T8 temper. The tensile tests were conducted at room temperature in accordance with ASTM standard E8 using a servohydraulic test machine [7]. Elongations were measured using back-to-back extensometers (0.3-inch gage length) mounted on the sides of the specimens or using fiducial mark analysis.

The 2195 tensile specimens were 0.1 inches thick and machined from the midthickness. Specimens from C415 cylinder 1 were 0.2 inches thick and machined from the midthickness. Specimens from cylinder 6 were full-thickness.

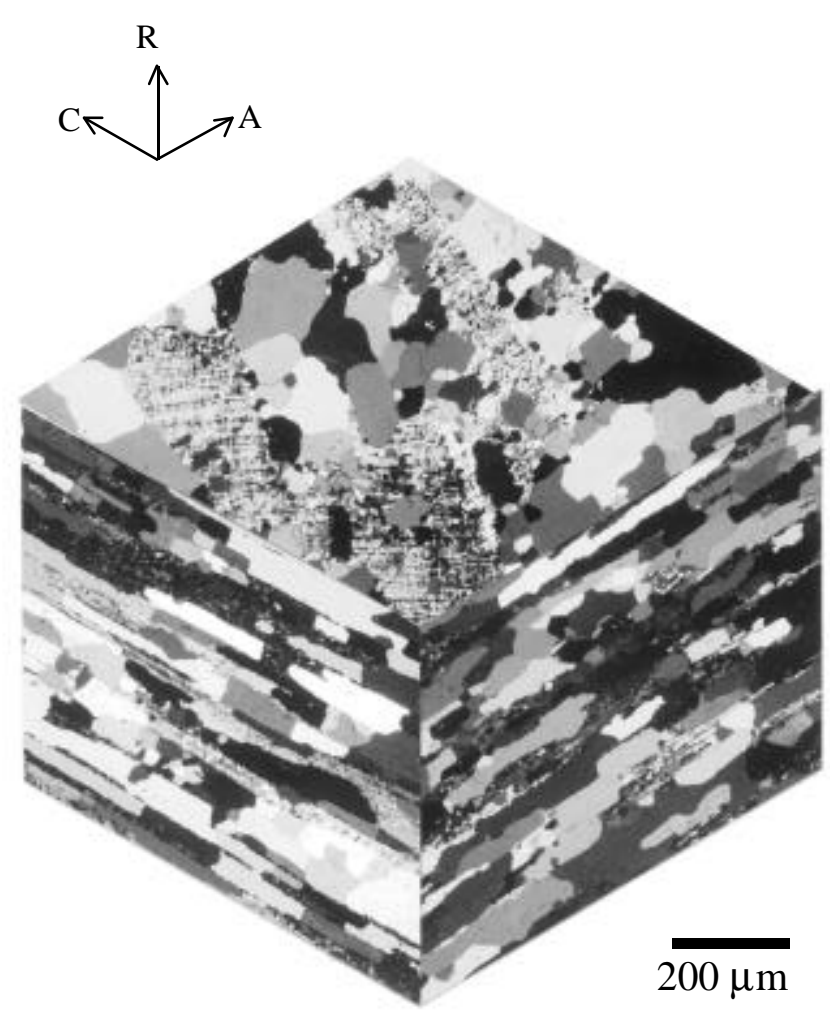

Figure 3. 2195-T4 Cylinder D at midthickness.

\section{Results and Discussion}

Alloy 2195

Examination of anodized samples of the T4 material revealed a partially recrystallized grain structure. For cylinder D, which experienced the least amount of total true shear-forming strain, the grain structure was fairly homogeneous through the thickness of the material. Structures resembling deformation bands were visible for cylinders $D$ and $\mathrm{A}$, as can be seen most clearly on the AC plane in Figure 3. The grain structure of cylinders $\mathrm{A}$ and $\mathrm{C}$ was less homogeneous through the thickness than was seen for cylinder D. As shown in Figure 4, this decrease in homogeneity was most pronounced for cylinder $\mathrm{C}$, which had experienced the greatest amount of total true shear-forming strain. While recrystallized areas were visible throughout the material, the outer region contained a smaller fraction of recrystallized grains; the inner region appeared to be more recrystallized with regions of fine, equiaxed grains. Large recrystallized grains were visible throughout 
the thickness. Thermomechanical processing to the T8 temper did not change the grain structure significantly.

Overall, the texture of the 2195 shear formed cylinders was complex but weak, with maximum intensities less than ten times random. The texture for all the 2195 cylinders generally increased with shear-forming strain and distance from the outer cylinder surface.

The texture of the 2195-T4 material tended towards an FCC rolling-type texture, if data is interpreted as $\{\mathrm{hkl}\} / / \mathrm{AC}$ plane and <uvw $>/ /$ A direction. As expected, cylinder $C$ exhibited the largest texture intensities, since it experienced the largest level of shear-forming strain. Cylinder C exhibited a Brass texture and a well-defined $\beta$-fiber. Cylinder A exhibited a Brass texture but no $\beta$-fiber. The $\beta$-fiber was not seen for cylinder $\mathrm{D}$. In the $\mathrm{T} 8$ temper, cylinder $\mathrm{C}$ still exhibited a marked deformation texture with a well-developed $\beta$-fiber at all three depths. However, a significant $\mathrm{RC}_{\mathrm{ND} 1}$ recrystallization component was detected for cylinder $\mathrm{C}$ at the $\mathrm{t} / 8$ and $7 \mathrm{t} / 8$ locations.

The effect of total true shear-forming strain on the yield and ultimate tensile strengths of the 2195-T8 cylinders is shown in Figure 5 for both the axial and circumferential orientations. Both the axial and circumferential yield and tensile strengths increased with shear-forming strain. At high shear-forming strain levels, the axial strengths were comparable to 2195-T8 plate from the SLWT program, but the circumferential strengths were substantially less. The anisotropy increased with increasing shear-forming strain and was associated with increased texture intensity.

Fiducial mark analysis indicated that the ductility was very high for the 2195 cylinders ( $26 \%$ between 0.5 -inch fiducial marks), though it decreased to around $20 \%$ with increasing shear-forming strain. The low circumferential strengths and the high ductility exhibited by the shear formed cylinders may indicate that the prescribed T8 heat treatment, derived for 2195 plate and sheet products, may need adjustment to optimize the strength/ductility combination for shear formed products.

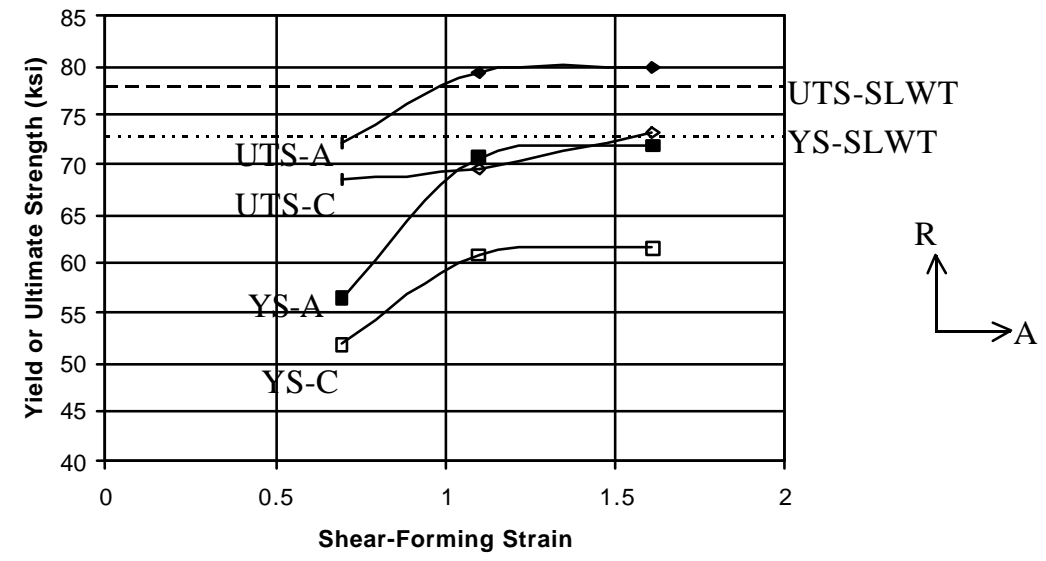

Figure 5. Tensile properties for 2195-T8 shear formed cylinders and plate [5].
Outer Surface

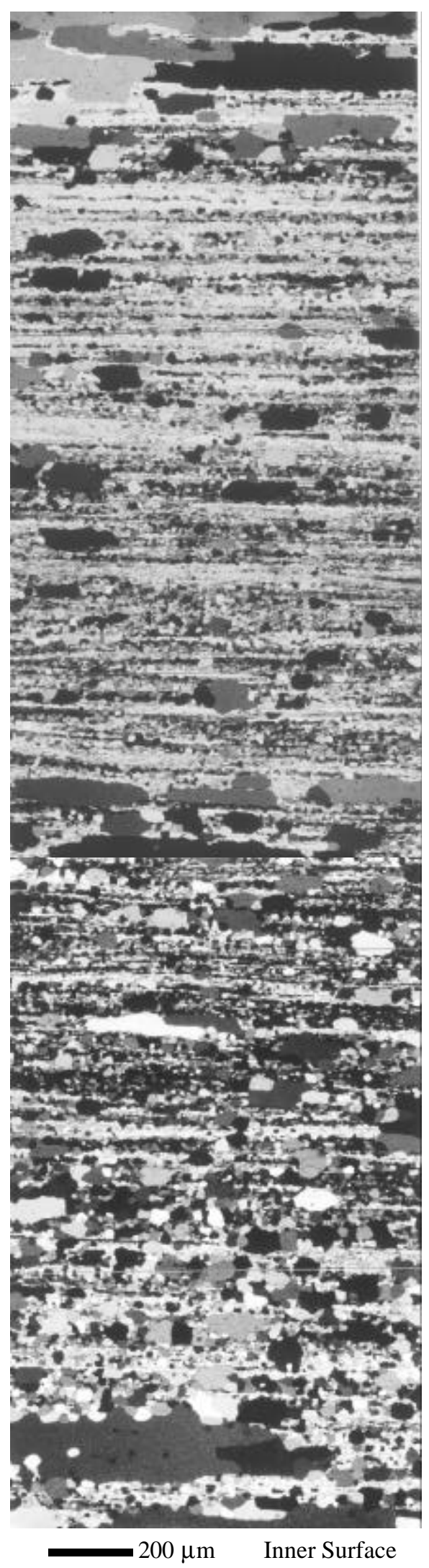

Figure 4. Through-thickness micrograph of 2195-T4 cylinder $\mathrm{C}$. 
Overall, C415-T3 cylinder 1 exhibited an almost completely recrystallized grain structure with clusters of small grains interspersed with coarse grains. In general, the grains became larger and more elongated with increasing depth below the outer cylinder surface.

Examination of cylinder 6 revealed a mostly recrystallized, non-uniform grain structure, shown in the through-thickness AR section in Figure 6. The image shows that the grain structure exhibited a marked transition from a fine, equiaxed structure for approximately the outer half of the cylinder to a coarse, elongated structure near the inner surface. The transition from fine to coarse grains occurred near midthickness. After examining cylinders 3 and 4, which were intermediate in thickness compared to cylinders 1 and 6, it was determined that the microstructure seen in cylinder 6 evolved gradually from that of cylinder 1 as shear forming strain increased. The grain structure probably resulted from refinement of the microstructure near the outer cylinder surface due to concentration of deformation in that area during the mandrel shear forming process.

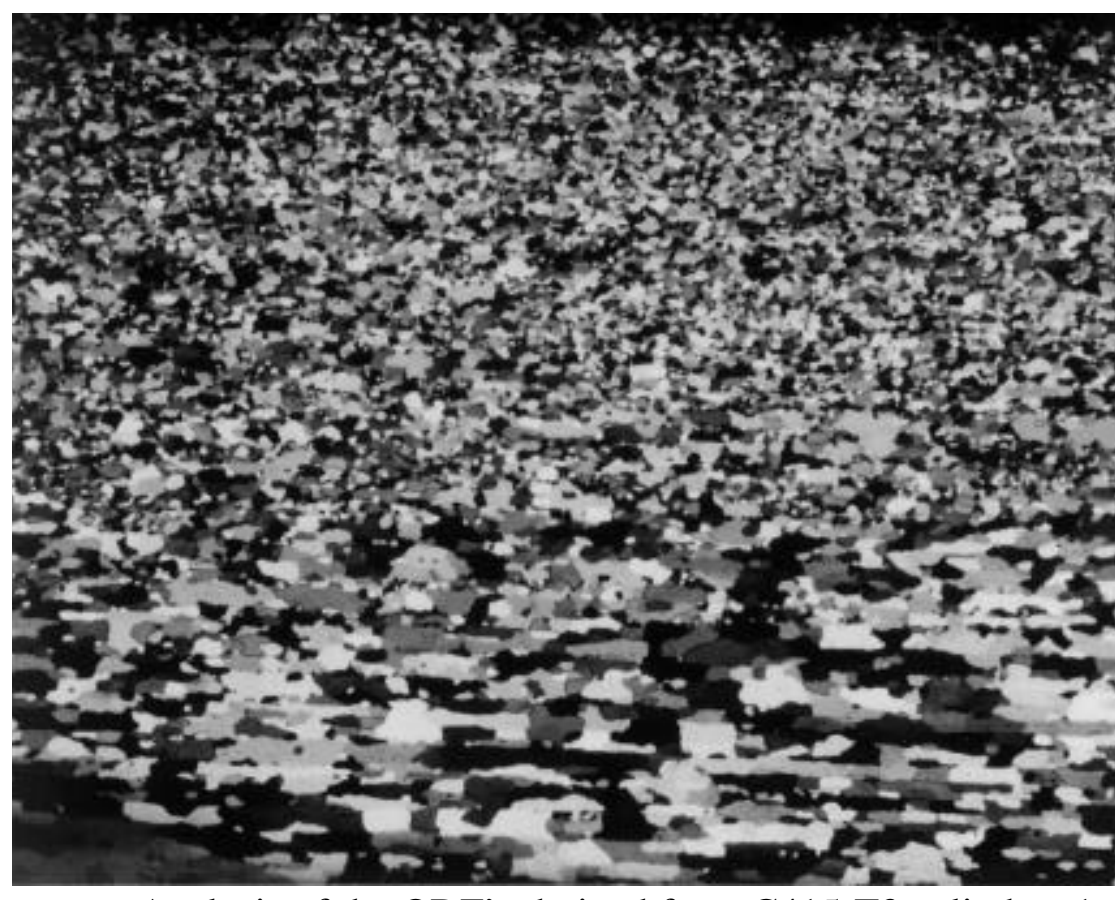

Outer Surface

Figure 6. Through-thickness micrograph of C415-T3 cylinder 6.

Analysis of the ODF's derived from C415-T3 cylinders 1 and 6 revealed a weak overall texture, with maximum intensities near six times random. For cylinder 1, the texture was nearly random at the $t / 8$ location. For depths $\geq t / 2$, a Cube component was detected. For cylinder 6 , both recrystallization and deformation texture components were observed. Cylinder 6 exhibited a Brass texture component at all depths and locations studied. In addition, the $t / 2$ locations in cylinder 6 showed a Shear ${ }_{1}$ component. The Cube texture component was seen only at the $t / 8$ locations in cylinder 6 , while the $\mathrm{RC}_{\mathrm{RD} 1}$ component was seen at $\mathrm{t} / 8$ and $\mathrm{t} / 2$; the $\mathrm{RC}_{\mathrm{TD} 1}$ and $\mathrm{Cu}$ components were observed mainly at $t / 2$ and $7 t / 8$. The definition of the $\beta$-fiber was greatest at $7 t / 8$. Flattening did not significantly alter the texture.

Table 4 shows the effect of shear-forming strain and aging procedure on yield strength and ultimate tensile strength for the C415-T8 shear formed cylinders, for both the axial and circumferential orientations. Data for C415-T8 sheet is also shown for comparison [8]. Aging directly to the T8 temper after extended room temperature storage usually resulted in greater yield and tensile strengths than material which was reprocessed to the T8 temper. This effect was most pronounced for the axial orientation. For the direct-aged material, the axial yield and ultimate strengths generally exceeded the corresponding circumferential strengths, while the opposite trend was noted for the reprocessed material. Overall, the yield and ultimate strengths were inversely proportional to shear- 
forming strain. The strengths for all $\mathrm{C} 415$ cylinders and orientations were typically within $5 \%$ of properties for C415-T8 sheet.

For C415-T8 cylinder 1, the ductility exceeded the $15 \%$ operating range of the extensometers for both the direct-aged and reprocessed conditions, while the range of ductility for cylinder 6 was 10-14\%. Fiducial mark analysis showed 20-27\% elongation for cylinder 1 and 11-16\% for cylinder 6. The decrease in ductility with increasing level of shear-forming strain was not expected since strength and ductility normally exhibit an inverse relationship.

Table 4. Tensile Properties for C415-T8 Shear Formed Cylinders and 0.090-inch Sheet.

\begin{tabular}{|c|c|c|c|c|c|c|}
\hline \multicolumn{2}{|c|}{} & \multicolumn{2}{c|}{ Yield Strength (ksi) } & \multicolumn{2}{c|}{ Ultimate Strength (ksi) } \\
\hline Cylinder & $\varepsilon$ & Orientation & Direct Aged & Reprocessed & Direct Aged & Reprocessed \\
\hline \multirow{2}{*}{1} & \multirow{2}{*}{0.72} & A & 75.11 & 69.21 & 80.74 & 77.11 \\
\cline { 3 - 7 } & & C & 73.85 & 73.20 & 80.06 & 78.72 \\
\hline \multirow{2}{*}{6} & \multirow{2}{*}{1.88} & A & 73.83 & 70.17 & 76.08 & 76.84 \\
\cline { 3 - 7 } & & C & 71.69 & 72.13 & 77.63 & 76.82 \\
\hline \multicolumn{2}{|c|}{ Sheet (T8) [8] } & L & T & \multicolumn{2}{|c|}{73.25} & \multicolumn{2}{c|}{78.60} \\
\cline { 3 - 6 } & & \multicolumn{2}{c}{} \\
\hline
\end{tabular}

\section{Conclusions}

The shear formed cylinders of 2195 and C415 exhibited unique grain structures and textures. For the processing conditions evaluated, the grain structure of the 2195 cylinders appeared partially recrystallized and became less homogeneous as shear-forming strain increased. The grain structure became finer and more equiaxed toward the inner surface of the cylinders. The texture was generally weak, but developed FCC rolling-type texture at higher shear-forming strains. Texture intensity increased with shear-forming strain and depth below the outer cylinder surface. The yield and tensile strengths of the 2195 material tended to increase with increasing shear-forming strain, while ductility showed the opposite trend.

The grain size for the $\mathrm{C} 415$ cylinders tended to increase with depth below the outer cylinder surface. As shear-forming strain increased, the microstructure evolved into layers of two different grain sizes. The cylinder subjected to the largest shear-forming strain exhibited fine grains for the outer half of the cylinder and coarse grains for the inner half. Overall, the texture was extremely weak, and the strength and ductility were both inversely proportional to shear-forming strain.

\section{Acknowledgement}

This work was performed while the author (LPT) held a National Research Council/ NASA-LaRC Research Associateship.

\section{References}

[1] E. Enright and P.J. Hartley, "Aluminum-Lithium Technology for Launch Vehicles. IR\&D M-40-D. Final Report (1994).

[2] M. Eckert and E. Schmeer, "Production of Motor Casings by Shear Forming," Proc. $32^{\text {nd }}$ Mechanical Working and Steel Processing Conference, vol. 28 (1990), pp. 297-305.

[3] David Furrer and Robert Noel, "Aluminum-lithium Cylinders," Advanced Materials and Processes, vol. 151, no. 5 (1997), pp. 59-60.

[4] R.E. Reinmuller, "Report on Allowables for 2195 Used for the Shuttle External Tank," presented at AeroMat '97, Williamsburg, VA (May 12-15, 1997).

[5] Al-Li Materials Database. Service Order SO-96-89818, prepared by Lockheed Martin-Manned Space Systems (Dec. 1996).

[6] Registration Record of International Alloy Designations and Chemical Composition Limits for Wrought Aluminum and Wrought Aluminum Alloys, Aluminum Association (1998).

[7] "Standard Test Method for Tension Testing of Metallic Material," Annual Book of ASTM Standards, vol. 03.01 (1999), p. 57.

[8] David Chellman et al., "Aluminum Alloy Development: HSR Airframe Technology-Metallic Materials." Final Report, Lockheed Martin Aeronautical Systems LG97ER0037 (1997), p. 71. 